\title{
Design of Ultrasonic Sensor and Ultraviolet Sensor Implemented on a Fire Fighter Robot Using AT89S52
}

\author{
Ipin Prasojo ${ }^{1}$, Phong Thanh Nguyen ${ }^{2}$, Omar tanane ${ }^{3}$, Nishith Shahu ${ }^{4}$ \\ ${ }^{1}$ Sarjana Terapan Elektromedik, ITS PKU Muhammadiyah Surakarta, Indonesia \\ 2 Director, Department of Project Management, Ho Chi MinhCity Open University, Vietnam. \\ ${ }^{3}$ Faculty of Sciences Ben M'sik, University Hassan II of Casablanca, Casablanca, Morocco \\ ${ }^{4}$ Departement of Electrical Engineering, Gujarat Technological University, India \\ rmprasojo@gmail.com ${ }^{1}$, phong.nt@ou.edu.vn ${ }^{2}$, omar.tanane@univh2c.ma ${ }^{3}$, nish2687@gmail.com ${ }^{4}$
}

\begin{abstract}
A firefighter is a task given by someone or a team to extinguish a fire that occurs when building a building. The officer took the danger of fighting the fire with a fire engine equipped with a water sprayer. Because of these dangers, a robot was made to help put out the fire. This research aimed to design a fire extinguisher robot using AT89S52 microcontroller as its controller. A DC fan controlled by a relay was utilized to extinguish the fire and a fire sensor (UV-Tron) was used to detect the presence of fire. The robot was driven by motor DC. It could detect the surrounding obstacles and possessed an ultrasound-based navigation system. If the ultrasound system detects an obstacle, the robot will automatically turn without colliding the obstacle or other things around it. The result of the research showed that the proposed fire extinguisher robot can detect fire as far as $\mathbf{5}$ meters and successfully extinguish the fire.
\end{abstract}

Keywords- fire fighter robot, flame sensor, ultrasound sensor, microcontroller

\section{INTRODUCTION}

Extinguishing fire carries risks to firefighters. Efforts to create robots capable of extinguishing fire have been made by several researchers. Numerous competitions concerning the robot have been held. It has designed a fire fighting robot using a camera to detect fire by analyzing digital images of fire images. Although based on images, the result of the test was quite satisfying, reaching a success rate of $93.3 \%$. However, viewed from the computational load, the load was very large compared to sensors that are indeed intended to fire. Many strategies have been developed so that the robots can track and detect sources of fire, but they are usually conducted using complex algorithms.

Several researchers have conducted research on firefighting robots. Derie designed and constructed a fully autonomous fire-fighting robot. The robot processed information from various sensors such as UV, IR and key hardware elements through the Motorola 68HC12 micro controller [1]. Altaf, Akbar and Ijaz designed and constructed Autonomous Fire Fighting Robots. The robot was built using an LDR sensor and a microcontroller as a robot controller [2]. $\mathrm{Xu}$ et al design and Implemented a mobile robot remote fire alarm system. The system consisted of an aSTC89C52 microcontroller, a fire detection sensor, and an object detection sensor. The fire detection sensor used a photoelectric and smoke, temperature, and fire sensors, while the object detection sensor used an infrared sensor [3].

Undug investigated fire locator, fire detectors and robots sent through an SMS. The system consisted of a fire detection system and a fire fighting robot. The fire detection system consisted of smoke sensors, a PIC microcontroller, and a GSM Module. The fire-fighting robot consisted of a fire sensor, and the fire sensor consisted of flame, infrared, and object detection sensors and a PIC microcontroller [4]. Hassanein studied an autonomous fire-fighting robot. The system consisted of object detection sensors using infrared and ultrasonic, and fire detection sensors using flame sensors and microcontrollers [5]. Maddukuri designed a low-cost and autonomous sensor-based fire-fighting robot. The robot consisted of a fire detection sensor consisting of infrared, smoke and temperature sensors, and an object detection sensor consisting of a barrier avoidance module and a microcontroller [6].

Engin conducted research on real-time and embedded system design of a fire-fighting robot. The system consisted of a fire detection sensor using UVtron and TPA 81, an object detection sensor with infrared and crash sensors, and an ARM Cortex-M4 core TM4CI23G type microcontroller [7]. Raju et.al. studied the development and implementation of Arduino microcontrollers based on dual mode fire extinguishing robots. The system consisted of a fire detection module, an object detection module, and an Arduino [8]. Prabha and Shivaanivarsha designed a fire extinguisher and supervising independent robots. The system consisted of a fire sensor, a smoke sensor, Zigbee, and a microcontroller [9].

Tulbure, Ceuca and Ilea examined the electronically controlled hexapod prototype for emergency situations. The system consisted of a Hexapod robot with a pyroelectric sensor for fire detection and a PIC type microcontroller [10]. Patel and Pancholi studied designed novel fire-fighting robot vehicle controlled by an android application. The system consisted of an ATMEGA32 microcontroller, a fire detection 
sensor using IR flame and LM35, and an object detection sensor [11]. Bose Developed and designed fire-fighting robots using cybersecurity. The system consisted of a microcontroller, a fire detection sensor using gas sensor and temperature sensor, and an object detection sensor [12].

Beside using a fire sensor to detect fire and an object detection sensor, several researchers used an ultrasonic sensor to detect objects in front of the robot. Freire, Bastos and Dynnikov investigated an agent-based ultrasonic sensing system for cellular robots. The robot used 16 ultrasonic sensors attached to its body to detect objects and walls in front of it [13]. Peri and Simon examined fuzzy logic control for autonomous robots (Peri and Simon, 2005). The robot used a fuzzy algorithm for robot control. The data from the fuzzy were obtained from the ultrasonic sensor [14]. Lewinger, Watson and Quinn studied obstacle avoidance behavior for biologically inspired cellular robots using binaural ultrasonic sensors. This insect-like robots used an ultrasonic sensor mounted in the front of the robot [15].

Xuan-Thu Le et al designed a smart phone robot system based on ultrasonic sensor. This 4-legged insect-like robot could detect objects in front by using ultrasonic placedin the front [16]. Aliyu et. Al. investigated ultrasonic proximity sensor induces automatic car collision avoidance systems [17]. The braking system was used by the robot using the ultrasonic sensor to detect objects in front of the robot. Azid et al examined the Lyapunov-based driverless vehicle in an obstacle-free environment. The system consisted of a microcontroller, an ultrasonic sensor, and a servo. It used the Lyapunov control [18].

Noman et. al. designed and implemented microcontrollerbased auxiliary robots for people with blind and blind autism. The system consisted of a robot with an ultrasonic sensor to detect objects in front, an infrared sensor to detect stairs, and a microcontroller [19]. Budianto et. Al. Analyzed artificial intelligence applications using back propagation neural networks and fuzzy logic controllers in autonomous cellular wall-following robots. The system consisted of an ultrasonic sensor and a microcontroller. Fuzzy algorithm was used in this robot [20]. Diaz investigated an ultrasonic indoor placement for smart environments in cellular application. This system used ultrasonic sensors to detect objects in an unknown environment [21].

The research conducted previously showed that an ultrasonic sensor was used to detect the objects in front of the robot. The research conducted by the author aimed to develop a wheeled robot prototype equipped with a fire detection sensor with ultrasonic and ultraviolet sensors to track, detect and extinguish fire to reduce the computational load. The sensors were mounted on the fire-fighting robot. This research is also following up the research on the object detection using only ultrasonic sensor.

\section{RESEARCH METHOD}

The subject of the research was a wheeled robot capable to explore a place. The robot was designed with 4 wheels and 2 DC motors. The work system made the robot able to avoid obstacles by turning right, left and retreating. The system was programmed using AT89S52 microcontroller [22]- [24].
Figure 1 displays the block diagram of the working system of the wheeled fire extinguisher.

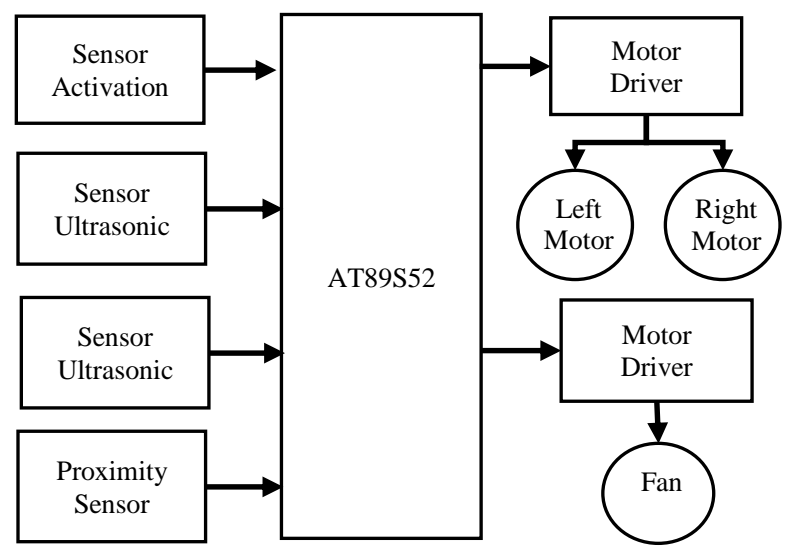

Fig. 1. Block diagram system.

\section{a. Main program}

The flowchart of fire-fighting robot main program is shown in Figure 2. When the switch is turned on, the program read the sound sensor. The program continues to read and waits until the sound sensor gets a sound response from the sound source. After the sound sensor is active, the program goes to the ultrasonic sensor reading subroutine. In the ultrasonic sensor [25]- [28] reading program, reading is done alternately from the topmost writing.

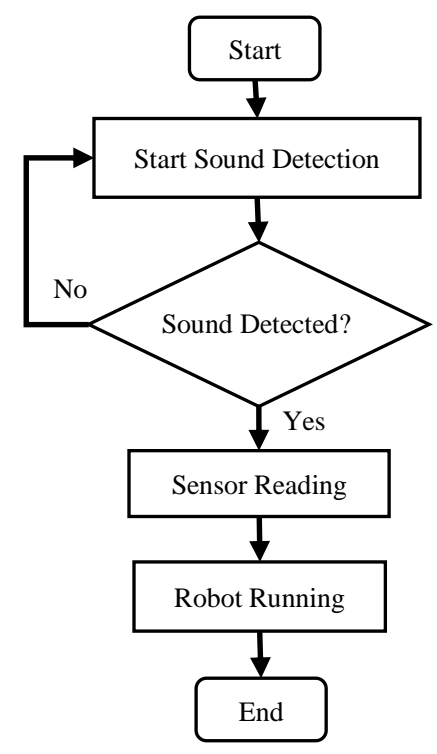

Fig. 2. Main work flow.

\section{b. Exploration program}

Figure 3 shows the flow diagram of the robot's motion tracking arrangement. The robot motion program is based on distance information obtained from ultrasonic sensors [29][31]. After the distance value is obtained from five ultrasonic sensors, the five distance values will be compared to determine where the robot will go. The way of the reading sensor to determine the robot direction was by reading the front ultrasonic sensor, and comparing the left and right distance. 


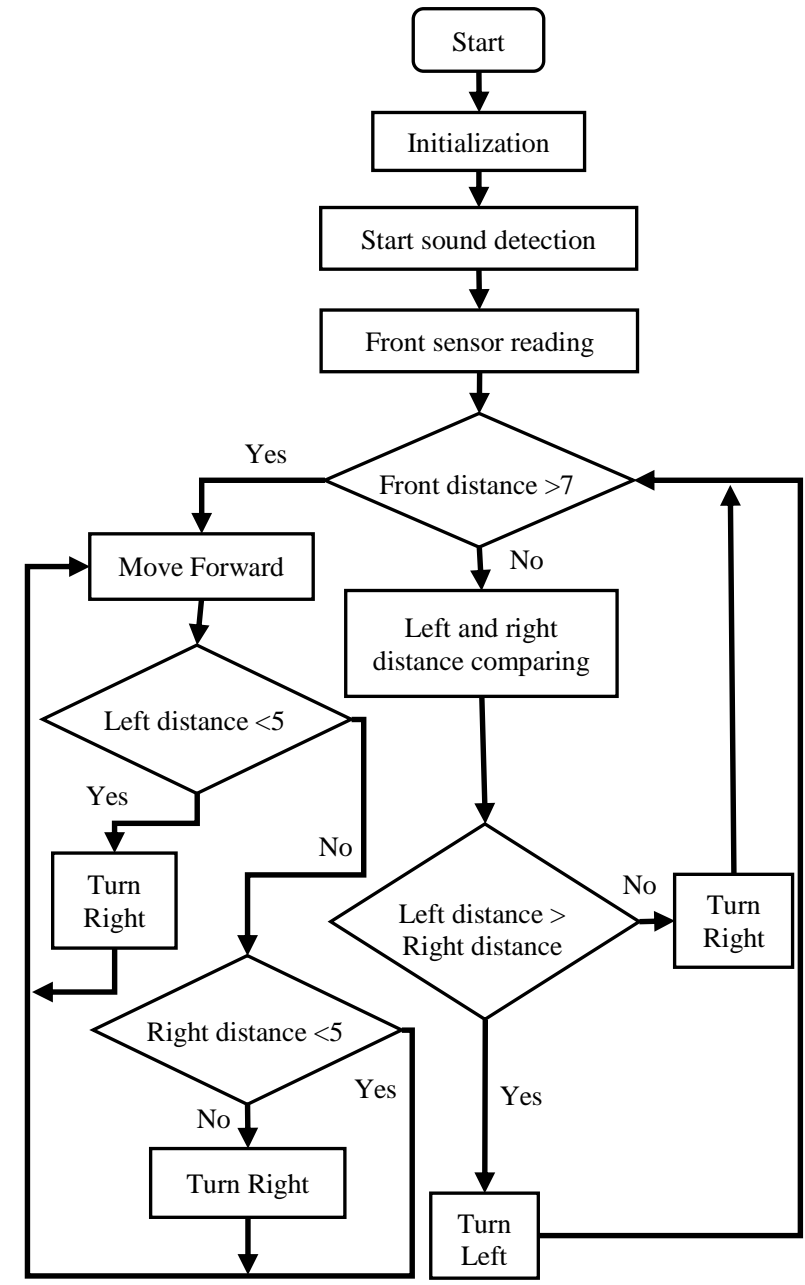

Fig. 3. Robot exploitation flow chart.

The template is used to format your paper and style the text. All margins, column widths, line spaces, and text fonts are prescribed; please do not alter them. You may note peculiarities. For example, the head margin in this template measures proportionately more than is customary. This measurement and others are deliberate, using specifications that anticipate your paper as one part of the entire proceedings, and not as an independent document. Please do not revise any of the current designations.

\section{IMPLEMENTATION}

\section{a. Sound activation test}

The first test was performed on the start button that used a sound sensor as robot's start control. The data were taken by measuring the sensitivity of the sensor to the sound response. The sound source was a $9 \mathrm{~V}$ buzzer. The test results showed that when the sound source was sounded in various distances, the sensitivity of the sensor to the sound source was identified. The sensor could receive voice responses from buzzers that sounded from a distance of $0-10 \mathrm{~cm}$, but not further than $10 \mathrm{~cm}$. The density of sound in the surrounding environment also greatly affected the sensitivity of the sensor. One of other sounds was the sound from the loudspeaker system that was in the same room.

\section{b. Fire sensor test}

The method to test this sensor was quite simple. Every time the sensor detected ultraviolet light generated by a candle flame, the sensor issued 1 pulse of $85 \mathrm{~ms}$. The distance has no effect on the width of the high pulse issued because this pulse is affected by the large capacitor mounted on the Cx pin.

\section{c. Fire sensor test and demonstration}

The test was performed with the help of a microcontroller using the external interrupt function. If there is a down transition on this external interrupt pin, the microcontroller will turn on all the LEDs connected to port 1 on the microcontroller. This test was carried out under bright light and in the distance of $30 \mathrm{~cm}$ from the candle to the sensor mounted on the robot.

The test also performed distance of up to $5.5 \mathrm{~m}$ because if further than $5.5 \mathrm{~m}$, this sensor could not respond. It was found that the test result was the same as it was of $30 \mathrm{~cm}$. The data proved that the UVTron Flame Detector could detect the candle light when the candle position was in the front because the UVTron Flame Detector was fitted with a protector to determine the absolute point of a candle.

\section{d. Ultrasonic sensor test}

The distance of the sound wave reflection was set in the program. The distance readings using ultrasonic sensor were displayed on an LCD. The ultrasonic sensor distance reading data towards time was presented in Table 1. From the table it can be seen that the distance of computational results deviates from the mean deviation of $7.23 \%$. This difference is possible due to a delay in program execution and the response of the sensor itself.

TABLE I. DISTANCE READING TOWARDS TIME

\begin{tabular}{|c|c|c|c|}
\hline Distance $(\mathrm{cm})$ & Time $(\mathrm{ms})$ & Sensor reading $(\mathrm{cm})$ & Error \\
\hline 3 & 0.095 & 3.268 & 8.93 \\
\hline 4 & 0.12 & 4.128 & 3.20 \\
\hline 5 & 0.161 & 5.5384 & 10.77 \\
\hline 6 & 0.198 & 6.8112 & 13.52 \\
\hline 7 & 0.22 & 7.568 & 8.11 \\
\hline 8 & 0.252 & 8.6688 & 8.36 \\
\hline 9 & 0.286 & 9.8384 & 9.32 \\
\hline 10 & 0.3 & 10.32 & 3.20 \\
\hline 11 & 0.33 & 11.352 & 3.20 \\
\hline 12 & 0.362 & 12.4528 & 3.77 \\
\hline
\end{tabular}

\section{e. Proximity sensor test}

Proximity sensor test was performed to determine the maximum distance the sensor could detect. This test was carried out by providing an LED indicator on the sensor output. So that when the sensor did not detect 'white' or exceeds the maximum distance, the LED turned off and when the sensor detected 'white', the LED turned on. The test was carried out in bright room, and the robot was in a standing 
position. The test results obtained that this sensor detected the white color of the floor at a maximum distance of less than $11 \mathrm{~cm}$.

\section{f. Robot system test}

The test on the robot system was carried out on a $248 \mathrm{~cm}$ x $248 \mathrm{~cm}$ x $30 \mathrm{~cm}$ multiplex boards with a thickness of 1.8 to $2 \mathrm{~cm}$. There are 4 rooms with fixed positions. The robot run on a track consisting of 4 rooms and several aisles. The source of the fire - a candle put in a white jar with a radius of $30 \mathrm{~cm}$ - was placed in one of the rooms in a fixed or unchanged position. Initially, the robot was placed in one corner of the track. It was observed how the robot found its target. The test was carried out 10 times to get the average time. The average robot travel time on the track without detecting the target was 324.00 seconds.

Figure 4 displays the graph of the robot system succession percentage. Based on the data of several tests, the average value time or the success rate of the robot in carrying out its duty was 717.79 seconds or 11 minutes 57 seconds. It can be concluded that the fire-fighting robot has successfully carried out its function with an average time record of 11 minutes 57 seconds.

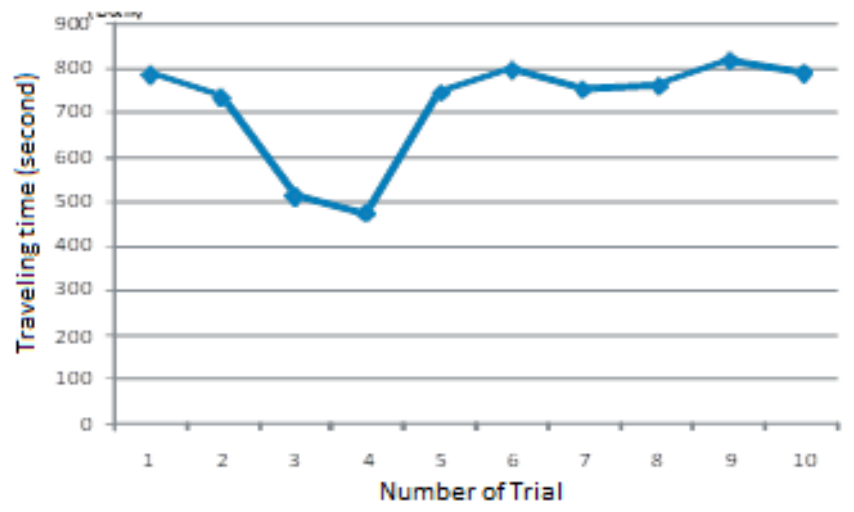

Fig. 4. Graph of robot system succession percentage.

\section{CONCLUSION}

A fire-fighting robot using the AT89S52 microcontroller has been successfully designed. By using an ultrasonic sensor, it can navigate through space properly without crashing into walls. The robot can find the source of the fire and then extinguish it by using a fan. The robot can detect sources of candle flame with an average travel time of 11 minutes 57 seconds.

\section{REFERENCES}

[1] S. Dearie, K. Fisher, B. Rajala, and S. Wasson, "Design and construction of a fully autonomous firefighting robot," in Proceedings: Electrical Insulation Conference and Electrical Manufacturing and Coil Winding Conference (Cat. No.01CH37264), 2001, pp. 303-310.

[2] K. Altaf, A. Akbar, and B. Ijaz, "Design and Construction of an Autonomous Fire Fighting Robot," in 2007 International Conference on Information and Emerging Technologies, 2007, pp. $1-5$.

[3] H. Xu, H. Chen, C. Cai, X. Guo, J. Fang, and Z. Sun, "Design and Implementation of Mobile Robot Remote Fire Alarm System," in 2011 International Conference on Intelligence Science and Information Engineering, 2011, pp. 32-36.
[4] J. Undug, M. P. Arabiran, J. R. Frades, J. Mazo, and M. Teogangco, "Fire Locator, Detector and Extinguisher Robot with SMS Capability," in 2015 International Conference on Humanoid, Nanotechnology, Information Technology,Communication and Control, Environment and Management (HNICEM), 2015, no. December, pp. 1-5.

[5] A. Hassanein, M. Elhawary, N. Jaber, and M. El-Abd, "An autonomous firefighting robot," in 2015 International Conference on Advanced Robotics (ICAR), 2015, pp. 530-535.

[6] S. V. P. K. Maddukuri, U. K. Renduchintala, A. Visvakumar, C. Pang, and S. K. Mittapally, "A low cost sensor based autonomous and semi-autonomous fire-fighting squad robot," in 2016 Sixth International Symposium on Embedded Computing and System Design (ISED), 2016, pp. 279-283.

[7] M. Engin, "Embedded and real time system design: A case study fire fighting robot," in 2016 5th Mediterranean Conference on Embedded Computing (MECO), 2016, vol. 2016, pp. 18-21.

[8] J. Raju, S. S. Mohammed, J. V. Paul, G. A. John, and Di. S. Nair, "Development and implementation of arduino microcontroller based dual mode fire extinguishing robot," in 2017 IEEE International Conference on Intelligent Techniques in Control, Optimization and Signal Processing (INCOS), 2017, vol. 2018Febru, pp. 1-4.

[9] P. S. Prabha and N. Shivaanivarsha, "A design of firefighting and supervising self-sufficient robots," in 2017 Third International Conference on Science Technology Engineering \& Management (ICONSTEM), 2017, pp. 858-862.

[10] A. Tulbure, E. Ceuca, and A. Ilea, "Electronically controlled hexapod prototype for emergency situations," in 2017 9th International Conference on Electronics, Computers and Artificial Intelligence (ECAI), 2017, vol. 2017-Janua, pp. 1-5.

[11] K. Patel and B. K. Pancholi, "A novel fire extinguishing robotic vehicle controlled by android application," in 2017 IEEE International Conference on Smart Technologies and Management for Computing, Communication, Controls, Energy and Materials (ICSTM), 2017, no. August, pp. 417-422.

[12] J. S. C. Bose, M. Mehrez, A. S. Badawy, W. Ghribi, H. Bangali, and A. Basha, "Development and designing of fire fighter robotics using cyber security," in 2017 2nd International Conference on AntiCyber Crimes (ICACC), 2017, pp. 118-122.

[13] E. O. Freire, T. F. Bastos, and V. Dynnikov, "An agent-based ultrasonic sensing system for mobile robots," in Proceedings of 40th Midwest Symposium on Circuits and Systems. Dedicated to the Memory of Professor Mac Van Valkenburg, 1997, vol. 1, pp. 646649.

[14] V. M. Peri and D. Simon, "Fuzzy Logic Control for an Autonomous Robot," in NAFIPS 2005 - 2005 Annual Meeting of the North American Fuzzy Information Processing Society, 2005, pp. 337342 .

[15] W. Lewinger, M. Watson, and R. Quinn, "Obstacle Avoidance Behavior for a Biologically-inspired Mobile Robot Using Binaural Ultrasonic Sensors," in 2006 IEEE/RSJ International Conference on Intelligent Robots and Systems, 2006, pp. 5769-5774.

[16] Xuan-Thu Le, Se-Bong Oh, Woo-Song Lee, Chon-Soo No, and Sung-Hyun Han, "Design of intelligent mobile robot system based on ultrasonic sensors," in 2007 International Conference on Control, Automation and Systems, 2007, no. 2, pp. 72-76.

[17] A. Aliyu, J. G. Kolo, O. O. Mikail, J. Agajo, B. Umar, and O. I. Aguagba, "An ultrasonic sensor distance induced automatic braking automobile collision avoidance system," in 2017 IEEE 3rd International Conference on Electro-Technology for National Development (NIGERCON), 2017, vol. 2018-Janua, pp. 570-576.

[18] S. Azid, K. Kumar, D. Lal, and B. Sharma, "Lyapunov based driverless vehicle in obstacle free environment," in 2017 2nd International Conference on Control and Robotics Engineering (ICCRE), 2017, pp. 53-56. 
[19] A. T. Noman, M. A. M. Chowdhury, H. Rashid, S. M. S. R. Faisal, I. U. Ahmed, and S. M. T. Reza, "Design and implementation of microcontroller based assistive robot for person with blind autism and visual impairment," in 2017 20th International Conference of Computer and Information Technology (ICCIT), 2017, vol. 2018Janua, pp. 1-5.

[20] A. Budianto et al., "Analysis of artificial intelligence application using back propagation neural network and fuzzy logic controller on wall-following autonomous mobile robot," in 2017 International Symposium on Electronics and Smart Devices (ISESD), 2017, vol. 2018-Janua, no. 1, pp. 62-66.

[21] E. Diaz, M. C. Perez, D. Gualda, J. M. Villadangos, J. Urena, and J. J. Garcia, "Ultrasonic indoor positioning for smart environments: A mobile application," in 2017 4th Experiment@International Conference (exp.at'17), 2017, pp. 280-285.

[22] H. Wen-tian and L. Jin-ping, "Research and Design of Intelligent Temperature Control System," in 2010 Second International Workshop on Education Technology and Computer Science, 2010, vol. 1, pp. 538-541.

[23] H. Wentian and L. Jinping, "Design of the Temperature Control System Based on AT89S51," in 2010 International Forum on Information Technology and Applications, 2010, vol. 2, pp. 63-66.

[24] E. Kuantama, L. Setyawan, and J. Darma, "Early flood alerts using Short Message Service (SMS)," in 2012 International Conference on System Engineering and Technology (ICSET), 2012, pp. 1-5.

[25] A. Tayab Noman, M. S. Khan, M. Emdadul Islam, and H. Rashid, "A New Design Approach for Gesture Controlled Smart Wheelchair Utilizing Microcontroller," in 2018 International Conference on
Innovations in Science, Engineering and Technology (ICISET), 2018, no. October, pp. 64-68.

[26] A. Berdich and G. Andreescu, "Master-Slave Tracking System for Mobile Robots," in 2018 IEEE 12th International Symposium on Applied Computational Intelligence and Informatics (SACI), 2018, pp. 000045-000050.

[27] J. Jean and F. Lian, "Implementation of a Security Micro-aerial Vehicle Based on HT66FU50 Microcontroller," in 2015 IIAI 4th International Congress on Advanced Applied Informatics, 2015, pp. 409-410.

[28] K. J. Yoon and N. S. Goo, "Development of a small autonomous flying robot with four-rotor system," in 2011 15th International Conference on Advanced Robotics (ICAR), 2011, pp. 150-154.

[29] S. Belgamwar and S. Agrawal, "An Arduino Based Gesture Control System for Human-Computer Interface," in 2018 Fourth International Conference on Computing Communication Control and Automation (ICCUBEA), 2018, pp. 1-3.

[30] E. F. Sinaga and S. Boentoro, "Development of a control system for human follower quadcopter," in 2017 International Conference on Smart Cities, Automation \& Intelligent Computing Systems (ICONSONICS), 2017, pp. 30-35.

[31] M. Abdul Kader, M. Z. Islam, J. Al Rafi, M. Rasedul Islam, and F. Sharif Hossain, "Line Following Autonomous Office Assistant Robot with PID Algorithm," in 2018 International Conference on Innovations in Science, Engineering and Technology (ICISET), 2018, no. October, pp. 109-114. 